\title{
The Influence of Gender Identities on Body Image and Breast Health Among Sexual Minority Women in Taiwan: Implications for Healthcare Practices
}

DOI:

10.1007/s11199-017-0793-4

\section{Document Version \\ Accepted author manuscript}

Link to publication record in Manchester Research Explorer

Citation for published version (APA):

Wang, Y-C., Griffiths, J., \& Grande, G. (2017). The Influence of Gender Identities on Body Image and Breast Health Among Sexual Minority Women in Taiwan: Implications for Healthcare Practices. Sex Roles.

https://doi.org/10.1007/s11199-017-0793-4

\section{Published in:}

Sex Roles

\section{Citing this paper}

Please note that where the full-text provided on Manchester Research Explorer is the Author Accepted Manuscript or Proof version this may differ from the final Published version. If citing, it is advised that you check and use the publisher's definitive version.

\section{General rights}

Copyright and moral rights for the publications made accessible in the Research Explorer are retained by the authors and/or other copyright owners and it is a condition of accessing publications that users recognise and abide by the legal requirements associated with these rights.

\section{Takedown policy}

If you believe that this document breaches copyright please refer to the University of Manchester's Takedown Procedures [http://man.ac.uk/04Y6Bo] or contact uml.scholarlycommunications@manchester.ac.uk providing relevant details, so we can investigate your claim.

\section{OPEN ACCESS}




\section{Sex Roles}

\section{The Influence of Gender Identities on Body Image and Breast Health Among Sexual Minority Women in Taiwan: Implications for Healthcare Practices --Manuscript Draft--}

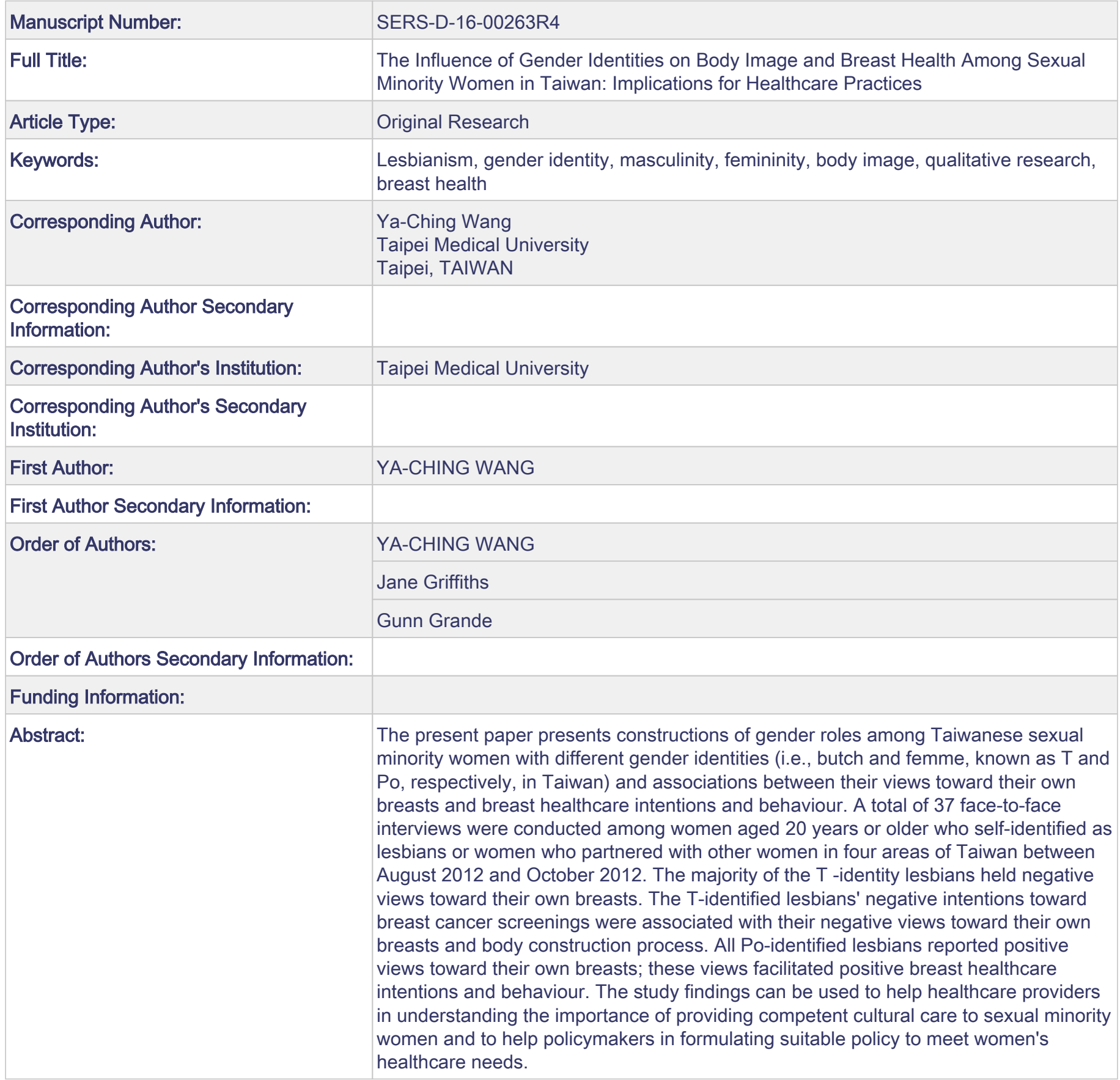




\section{Title Page}

\section{Article title:}

The Influence of Gender Identities on Body Image and Breast Health Among Sexual Minority Women in Taiwan: Implications for Healthcare Practice

\section{Journal name:}

Sex Roles

The full name and details of the corresponding author:

1. Dr. Ya-Ching, Wang

School of Nursing, College of Nursing, Taipei Medical University

No. $250 \mathrm{Wu}-\mathrm{Hsing}$ St. Taipei City, Taiwan 110

Email: yaching001@tmu.edu.tw

Phone number: +886-2-27361661 \#6327

The full names and details of all co-authors of the paper:

2. Dr. Jane Griffiths

School of Nursing, Midwifery and Social Work, University of Manchester, Jean McFarlane Building, Oxford Road, Manchester, M13 9PL, UK.

Email: Jane.Griffiths@manchester.ac.uk 


\section{Professor Gunn Grande}

School of Nursing, Midwifery and Social Work, University of Manchester, Jean McFarlane Building, Oxford Road, Manchester, M13 9PL, UK.

Email: Gunn.Grande@ manchester.ac.uk

\section{Acknowledgement:}

The authors would like to thank all of the participants who took part in this study and staff in the LGBT organizations and communities who assisted in advertising the study. 
The Influence of Gender Identities on Body Image and Breast Health Among Sexual Minority Women in Taiwan: Implications for Healthcare Practices

\author{
Ya-Ching Wang \\ Taipei Medical University \\ Jane Griffiths and Gunn Grande \\ University of Manchester
}

\begin{abstract}
Author Note
Ya-Ching Wang, School of Nursing, College of Nursing, Taipei Medical University; Jane Griffiths, School of Nursing, Midwifery and Social Work, University of Manchester; Gunn Grande, School of Nursing, Midwifery and Social Work, University of Manchester The authors would like to thank all of the participants who took part in this study and staff in the LGBT organizations and communities who assisted in advertising the study. Correspondence concerning this manuscript should be addressed to Ya-Ching Wang, School of Nursing, College of Nursing, Taipei Medical University, No. 250 Wu-Hsing St. Taipei City, Taiwan 110. Email: yaching001@tmu.edu.tw
\end{abstract}




\begin{abstract}
The present paper presents constructions of gender roles among Taiwanese sexual minority women with different gender identities (i.e., butch and femme, known as T and Po, respectively, in Taiwan) and associations between their views toward their own breasts and breast healthcare intentions and behaviour. A total of 37 face-to-face interviews were conducted among women aged 20 years or older who self-identified as lesbians or women who partnered with other women in four areas of Taiwan between August 2012 and October 2012. The majority of the T -identity lesbians held negative views toward their own breasts. The T-identified lesbians' negative intentions toward breast cancer screenings were associated with their negative views toward their own breasts and body construction process. All Poidentified lesbians reported positive views toward their own breasts; these views facilitated positive breast healthcare intentions and behaviour. The study findings can be used to help healthcare providers in understanding the importance of providing competent cultural care to sexual minority women and to help policymakers in formulating suitable policy to meet women's healthcare needs.
\end{abstract}

Keywords: Lesbianism, gender identity, masculinity, femininity, body image, qualitative research, breast health 
The Influence of Gender Identities on Body Image and Breast Health Among Sexual Minority Women in Taiwan: Implications for Healthcare Practices

Both sexual orientation and gender identity among sexual minority populations have been suggested to influence their access to healthcare services and the quality of care they receive (Institute of Medicine, 2013). In 2015 in the United States, the Centres for Medicare and Medicaid Services and the Office of the National Coordinator for Health Information Technology have stated that information regarding sexual orientation and gender identity must be collected from patients using all electronic health record systems certified under the Meaningful Use incentive program (Cahill, Baker, Deutsch, Keatley, \& Makadon, 2016).

In Taiwan, binary gender labels have been widely used among Taiwanese lesbians since the 1980s (Zhang, 2011). The label T, originally derived from the English word "tomboy," is defined by Abate (2011, p. 407) as "a girl who prefers the activities, toys, and usually attire of a boy," explaining that "this code of female conduct has assumed both masculine and feminine forms, been found in both urban and rural locales, [and has] been associated with both heterosexual and homosexual sexualities." However, in Taiwan, T only refers to a masculine or butch lesbian because of the $\mathrm{T}$ bar culture and substantial media influence (Chao, 2001). The counterpart to T is Po. The term Po serves as a suffix in Mandarin Chinese; the Chinese "laopo" means wife, in this case referring to a T lesbian's female partner (i.e., a feminine or femme-identified lesbian) (Chao, 2000, 2002).

Chao $(1997,2000,2001,2002)$ conducted an ethnographic field study between 1993 and 1994 to explore the relationship between nation building and the process of lesbian gender identity formation in Taiwan. The study recruited 76 lesbians from bars in Taipei and Taichung as well as 30 feminists who were members of Taiwan's Queer Rights Movement. Chao (2000) indicated that the labels T and Po were created in the 1960s when the first waves of Taiwanese modernisation and industrialisation were initiated by the governments of the 
United States and Japan through financial investment. The traditional economy and lifestyle collapsed, resulting in a large-scale migration from rural to urban and industrial areas. These changes were also reflected in the historical transformation of gender roles. Traditionally, Taiwanese women were required to stay at home, confined to their household. Urbanisation and industrialisation in Taiwan changed women's lifestyles and employment prospects. Numerous young women came to populous Taiwanese cities to work in clubs and factories. A well-known red-light district, originally established at the end of the Japanese colonial period, was further developed during the early 1960s as a product of American GI culture. Lesbian sex workers usually gathered at bars to socialise and to pick up sex partners. A lesbian community began to form, cultivating the lesbian gender identities of $\mathrm{T}$ and Po (Chao, 2000, 2001).

Although the identities of T and Po were created in the 1960s, they did not become widely known until the establishment of the first T bar in 1985. Wang You Gu [ForgetSadness Valley], opened by a T-Po couple in a Taipei red-light district (Chao, 2000), was a setting for lower-class T lesbians and Po sex workers from the neighbourhood to gather. Eventually, more $\mathrm{T}$ bars were opened in the three newest and most Westernised Taiwanese cities: Taipei, Taichung, and Kaohsiung (Chao, 2000, 2001). The T bar culture strengthened the lesbian community and the gender identities of $\mathrm{T}$ and Po became the norm (Chao, 2000).

In February 1990, the first lesbian organisation，我們之間［Between Us], was formed in Taiwan; its members worked to develop international contacts and sent a delegation to an Asian lesbian conference held in Bangkok in the same year (Fishel, 1994). Initially, the members included college students from feminist study groups as well as $\mathrm{T}$ and Po lesbians from local communities. However, conflict arose between the younger (feminists) and the older cohorts (traditional T- and Po-identified lesbians) in the organisation. In the first year, several of the $\mathrm{T}$ and Po lesbians participating in the organisation in its initial months 
withdrew their participation because of internal tension, differing opinions regarding roleidentification and priorities, and frustration over inefficiency and the disorganisation of meetings. The original feminist members aimed to alleviate the isolation experienced by the $\mathrm{T}$ and Po members by creating an alternative space for socialising outside of bars and away from alcohol; they did not aim to politicise these efforts or have the roles of the $\mathrm{T}$ and Po members called into question. Furthermore, because of these conflicts, the organisation changed its original membership recruitment methods; in addition to the original older- and younger-generation lesbians, younger lesbians, who were mainly feminists, were invited and recruited into the organisation (Chao, 2000, 2001).

The concept of bufen ('undifferentiated lesbian' in English) emerged in the 1990s with the rise of feminism. Cheng (1997), a contemporary feminist, indicated that the roles played by $\mathrm{T}$ and Po lesbians and the behavioural norms practised in local communities differed considerably from those in the broader society. According to Cheng, erotic roles and responsibilities are equal in bufen relationships. During this period, the lesbian identity in Taiwan was no longer perceived to be dichotomous; moreover, other categories have been proposed as subgroups in recent years including bufen pian T and bufen pian Po (Chiang \& You, 2011). Bufen pian T refers to a lesbian who identifies herself as bufen, but who shares some characteristics with T lesbians such as a masculine appearance (e.g., less visible breasts while wearing breast bindings). By contrast, the term bufen pian Po refers to a lesbian who identifies herself as being between Po and bufen categories, usually having a feminine appearance (e.g., wearing a bra and makeup and having long hair). However, Zhang (2011) indicated that although new gender labels have emerged, most Taiwanese lesbians still use binary gender labels (i.e., $\mathrm{T}$ and $\mathrm{Po}$ ), further showing that the number of $\mathrm{T}$ lesbians exceeds that of Po lesbians.

The $\mathrm{T}$ and Po identities enable women to structure expectations regarding personal 
identity, social interactions, and romantic exchange within Taiwanese lesbian culture (Halberstam, 1998; Levitt \& Hiestand, 2004; Levitt, Gerrish, \& Hiestand, 2003). The sharing of roles and responsibilities between the members of a T-Po couple is considered to reflect traditional dichotomous heterosexual roles between men and women (Cheng, 1997; Zhang, 2011). The construction of $\mathrm{T}$ and Po identities requires a process of body transformation. Transformation of a T's body involves a series of defeminisations (Chao, 2000). Wearing breast bindings is a significant act in defeminisation and self-identification for T lesbians, rendering the breasts—-socially defined feminine sexual characteristics—invisible. In a Taiwanese online survey conducted by Kuang, Mathy, Carol, and Kazuhiko (2004), over 70\% of 38 self-identified T lesbians attempted to hide their breasts. Chao $(1997,2000,2001)$ has determined that a T's breasts are hidden because they may provoke heterosexual men's amorous desire and attention, typically directed toward heterosexual women. Furthermore, the breasts are bound not only to distance $\mathrm{T}$ lesbians from heterosexual women, but also to visibly signal the crucial distinction between T and Po lesbians. Chao (1997) indicated that the T-Po division in Taiwan is substantially evidenced by Ts' breasts, which are viewed as non-corporeal and nonexistent by both $\mathrm{T}$ and Po lesbians. According to conventional bodily boundaries between Taiwanese T and Po lesbians, Ts' breasts cannot be seen or touched by Po lesbians, who are expected not to bind their breasts.

Similar findings have been presented by recent Taiwanese studies. Hong (2013) interviewed seven lesbians who had experience wearing breast bindings in 2010, identifying four reasons the women wore breast bindings: (a) to identify their sexual orientation, (b) to avoid a crisis of self-identification induced by an unsuitable choice of erotic partner, (c) to strengthen their gender identity, and (d) to promote sexual attraction. Hong indicated that these lesbians' use of breast bindings is strongly associated with mainstream lesbian culture, traditional heterosexual identification, and social expectations. In addition, Su (2005) claimed 
that wearing breast bindings is an action taken by lesbians to control their own bodies and to develop self-identification. However, Cheng (1997) argued that this action strongly relates to heterosexual identification, involving mimicking the appearance of men.

In the previous decade, T lesbians' views toward their own bodies and women's use of breast bindings have been found to be fluid and influenced by their social surroundings (Chan, 2000; Peng, 2008). Peng (2008) indicated that T lesbians initially considered their breasts as troublesome traits of the female body, posing a challenge in forming a masculine identity. Regardless of Ts' efforts in dressing themselves to appear masculine, their breasts reveal their true sex, resulting in a physical and psychological imbalance. The attitudes of Ts' partners and friends toward breasts, along with Ts' own experiences regarding their bodies and self-identification, have been observed to change Ts' views toward breasts and to assist them in accepting their female bodies. Ts' views toward their own breasts are transferable; their gender identity, gender expression, and body image interact with the social environment. Similar findings were presented by Chan (2000), who interviewed two $\mathrm{T}$ and five bufen lesbians aged 21-33 years-old. Their gender identity and gender expression were determined to be influenced by social interaction, mainly with their friends.

Previous studies have revealed that lesbians' gender identity and gender-role expression might affect their utilisation rates of healthcare services, satisfaction with healthcare services, and experiences in medical and mental healthcare settings. Hiestand, Horne, and Levitt (2007) found that both gender identity and gender-role presentation impacted sexual minority women's experiences in the healthcare setting in the United States. The researchers examined the experience of discrimination in the healthcare setting among a sample of 220 butch-identified women and 296 femme-identified women. The butch women reported poorer treatment within the healthcare setting and greater difficulty in finding lesbian-affirmative physical healthcare practitioners. Fish and Wilkinson (2003) explored 
barriers to breast self-examination (BSE) utilisation among 218 British lesbians who had never engaged in BSE. Approximately 7\% of the participants in Fish and Wilkinson's study reported that feelings of embarrassment and discomfort about their own breasts were factors preventing them from utilising BSE.

Another study conducted in the United States, enrolling 417 heterosexual women and a total of 213 lesbians and bisexual women aged 40-75 years-old (Clark et al., 2009) found that body image was one of the most common barriers toward delaying or avoiding cancer screening, further finding that sexual orientation was a factor preventing their utilisation of breast screenings. Nevertheless, considering previous evidence, there remains a lack of evidence concerning the associations between the gender identity of women sexual minorities and their breast healthcare utilisation and intentions. Thus the purpose of the current study was to describe constructions of gender roles among Taiwanese sexual minority women with different gender identities and to identify the associations between the women's views toward their own breasts and their breast healthcare intentions and utilisation by applying interview findings from an exploratory qualitative study.

\section{Method}

\section{Participants}

Participants in the current study include 37 self-identified lesbians or women who partnered with other women. Most of the women self-reported as masculine lesbians (T and bufen pian T lesbians, $n=23$ ) followed by feminine lesbians (Po lesbians, $n=10$ ). The gender label bufen $(n=4)$ was applied least frequently among the participants. No participant self-identified as bufen pian Po. The ages of the women ranged from 21-57 years-old, with a mean age of 32.4 years $(S D=8.48)$. Most of the participants reported their relationship status as partnered $(n=22 ; 59.5 \%)$, had a full-time job $(n=25 ; 67.6 \%)$, and had a college or graduate degree $(n=27 ; 72.8 \%)$. 
Of the 37 participants, 13 (35\%) woman had never practiced a breast selfexamination, 1 (2.7\%) woman practiced BSE only once, 15 (41\%) practiced BSE irregularly (not monthly), and $8(22 \%)$ practiced the screenings regularly (monthly). Among Taiwanese women, a free biennial mammogram is provided under the Taiwanese breast cancer, oral cancer, and colorectal cancer screening programmes. Eligible women include those aged 4569 years-old and those aged 40-44 years-old who have first- and second-degree relatives (grandmother, mother, daughter or sister) with breast cancer. Of the 37 participants, a majority of the women $(34,92 \%)$ were not eligible for having a free mammogram and had never had the screening. Only three participants were eligible. One had the screenings regularly, one had the screenings only one time, and one had never had it.

\section{Recruitment}

Purposive and snowball sampling strategies were employed to locate potential participants for our current study. The initial sampling was purposeful, driven by the aim of incorporating variation in the sample in order to acquire rich and useful information about the topic to be researched. Snowball sampling was employed as the second method to recruit participants with specific characteristics - in particular, lesbians of older age (aged 40 years and older).

Advertisements for interviewees were circulated to five LGBT organizations and one feminist bookstore. An appointment was made with all of the organisations' managers and the bookstore's owner so as to explain the aim of the study and the procedures for data collection and data protection. In addition, the study's posters, flyers, participant information sheets, and consent forms were given to the managers and the bookstore owner at the end of the meeting to advertise the study. The staff members in the organisations who met inclusion criteria were invited to participate. Posters and flyers were used to advertise the study to recruit other participants. With managers' consent, the study was advertised on the organisations' websites, 
the publishing company owner's Facebook page, and a lesbian discussion board to ensure that a maximal number of lesbians would learn about and participate in our study. In addition, the study was announced at the beginning of the organisations' regular meetings with manager's consent; the study's purpose, methods, and potential harm and benefits were explained in line with our university ethics review and approval.

Prospective interviewees contacted the first author (the interviewer) by email or phone to express interest in the study. The author then sent a flyer, a participant information sheet, and a consent form to the individuals via email and discussed the study's purpose and the inclusion criteria with the women via phone. The study's criteria for inclusion were: selfidentify as a lesbian or woman who partnered with other women and age 20 years or older at the time of the interview. Lesbians who had been diagnosed with breast cancer were excluded because their breast healthcare behaviours, beliefs, or expectations tend to differ from those of women with no history of breast cancer (Clark, Bonacore, Wright, Armstrong, \& Rakowski, 2003; Lopez et al., 2009). The author explained the purpose of the study and the interview process, and all study participants received a gift (about US \$10) for participating. A face-to-face interview meeting was scheduled for all women who expressed interest. Meeting time, date, and place of interview were decided by the participants in order to ensure the women felt comfortable and safe when taking about the topics.

Among the 39 lesbians originally recruited to participate, two lesbians, initially contacted the researcher by email, agreed to take part in the study, but they did not reply to emails about arranging an interview. A second email was sent a week after the first email in order to ensure that the individuals received the emails. However, there was still no response from the women by the time the data collection had finished.

\section{Data Collection}

Face-to-face interviews lasting about 42 minutes to 1.5 hours were conducted by the 
first author in locations selected by participants, which comprised participants' homes, a consulting room of the Taiwan LGBT Hotline Association, and public places (e.g. cafes, tea rooms or restaurants). Interruptions were more likely to occur if the interviews were conducted in a public area during the weekend. In order to limit possible interruptions, to ensure participants' confidentiality, and to make sure that they felt comfortable to talk, the interviewer went to the tea room or restaurant 30 minutes earlier and chose a table which would lead to fewer interruptions, provide more privacy, and where there were no other customers sitting nearby. Before the interview started, the researcher introduced herself and asked the participant whether the place was appropriate to discuss issues related to their views on breast cancer, breast healthcare services, and their own breasts.

The purpose, method, and processes of the study were then explained to participants; furthermore, written informed consent and permission to use a recorder were obtained. A topic guide was used to facilitate discussions about the lesbians' breast healthcare intentions and behaviours as well as corresponding influencing factors. There were eight questions included in the topic guide: "What do you know about breast cancer screenings?"; "Could you please talk about your experiences with breast cancer screenings?"; "What are factors that influence you in practicing breast self-examinations?"; "What are factors that influence/will influence you in obtaining breast cancer screenings?"; "What do you think about breast healthcare services in Taiwan?"; "What are factors that influence you in obtaining breast healthcare services?"; "In your view, what is the meaning of breast cancer?"; and "What do you think about breast cancer?" The topic guide was then slightly modified based on preliminary data analyses. Further questions were added to explore emerging issues in more depth—for example, "What are functions/meanings of your own breasts for you?" and "How do these views affect your breast healthcare intentions and/or behaviours?"

\section{Researcher Positionality and Reflexivity}


The primary researcher and first author, a Taiwanese cis-woman aged 31 years-old and a nursing $\mathrm{PhD}$ student, recruited participants and conducted all of the interviews. She shared the same physical gender, race, age, and social-cultural background with most interviewees, all of which were considered to help develop a relationship with the participants. However, her identification as a heterosexual woman potentially influenced the data collection process. Prior to the interview, the researcher and the participants would often engage in 15 to 30 minutes of informal conversation, and it was at this point that the individuals would often inquire whether the researcher was a lesbian too. When the researcher described herself as heterosexual, questions were asked by the participants about her motivation for conducting the study and her views on homosexuality. The researcher was identified as an outsider by the participants, which may have developed a barrier at the beginning of the interview. For example, some participants expressed: "I do not think you will understand why we think ..." When met with this situation, the researcher asked participants to explain their views, feelings, and past experiences of not being understood, asking questions such as "Can you explain what you mean....?" or "What do you mean...?" These questions helped clarify the ideas that the participants reported and identify factors that influenced the lesbians' behaviours and intentions regarding breast cancer screenings. A reflective journal was used throughout the study's data collection and analysis to help the researcher assess her influence, interpretations, and assumptions.

The second and the third authors are White heterosexual women, English speakers, and supervisors of the first author. Both have methodological expertise in qualitative research and have rich experiences of supervising research projects of students with different races, lifestyles, and backgrounds. During data collection and analysis, regular meetings were held with the interviewer and her two supervisors to enhance the rigor of the study.

\section{Data Analysis: Modified Grounded Theory}


Grounded theory strategies enable researchers to study new and emerging areas in need of investigation, to examine topics and related behaviours from different aspects, to uncover the beliefs and meanings that underlie actions, and to show how logic and emotion combine to affect how individuals respond to events or handle problems through action and interaction (Corbin \& Strauss, 2015). Usually it is used to generate a theory via the strategies of open coding, axial coding, and selective coding (Holloway \& Todres, 2007). Because the topic of our current study had never been studied in Taiwan, to our knowledge, and we aimed to gain comprehensive explanations of the women's behaviours and intentions to breast cancer screenings, grounded theory strategies were considered appropriate. However, it should be noted that the purpose of this study was to explore the factors associated with sexual minority women's breast healthcare behaviours and intentions in Taiwan, not to build a theory. We, therefore, did not integrate core categories to build a theory nor use theoretical sampling. Instead modified grounded theory procedures were applied as described in the following.

Corbin and Strauss (1990) indicate that if researchers are simply concerned with exploring or describing phenomena, open coding and axial coding complete the analysis. The aim of open coding is to break down and conceptualize the data, and it starts as soon as the researcher has collected the data. Types of open coding include descriptive coding (for example, "accepting advice") and in vivo coding (a direct quotation from the data). Robson (2011) suggests that open coding is essentially interpreting rather than summarizing. Axial coding involves linking together the categories developed through the open coding process (Robson, 2011). Corbin and Strauss (2008) indicate that axial coding leads to an understanding about the central phenomenon associated with an idea in terms of the context, the conditions that gave rise to it, and the action and interaction strategies by which it is dealt and their consequences. In this current study, we used open coding and axial coding to 
explore factors associated with Taiwanese sexual minority women's breast healthcare intentions and behaviours and to understand how these factors were associated with the women's breast healthcare intention and behaviours.

The data collection and data analysis occurred simultaneously in order to preliminarily identify the factors influencing Taiwanese lesbians' breast healthcare behaviours and intentions and to assess whether the data had approached saturation. Data saturation in our study occurred when no new themes (influencing factors) associated with the women's breast healthcare behaviours and intentions were identified. There were four phases included in the data analyses (Halcomb \& Davidson, 2006, p. 41). The first involved making field notes and reflective journalizing immediately after an interview: After each interview, the interviewer made field notes to record the interview setting, the interactions between the interviewer and the interviewee, observations on the interviewee's reactions during the interview process, and a reflection of the interviewer's influence. The second phase included listening to the audio recording and amending/revising the field notes: After the researcher completed the field notes and the reflective journal, the researcher listened to the recording, consulting the notes in order to ensure that they provided an accurate reflection of the interaction. The recording was compared with the notes, and the notes were revised where necessary by the researcher.

The third phase involved listening to the audio recording and making transcriptions concurrently: Each recording was listened to carefully by the researcher and selective transcription was conducted to capture data associated with the women's breast healthcare intentions and behaviours (the influencing factors). Unlike traditional word-by-word transcription, the researcher identified the influencing factors while listening to the recordings and only transcribed key phrases when participants reported influencing factors-for example, their concerns about having a mammogram: "Some lesbians feel uncomfortable 
about seeing a physician." This method of transcribing the data was used to help the researcher to understand, interpret, and categorize the data (Halcomb \& Davidson, 2006). However, this strategy could potentially cause the researcher to miss some of the keywords and/or terms and thus lead to incorrect interpretations or the wrong categorization of the data. In order to avoid this possibility, the researcher listened and selectively transcribed at least three times before doing a more detailed data analysis.

The final phase mainly focused on audio-coding (both open coding and axial coding) of the audio recordings. The audio-recordings, field notes, reflective journals, and transcriptions were imported into Nvivo 10. Each interview was listened to again in consultation with the transcription. The data were examined for each concept that the participant proposed. Open coding was made directly in the audio recording using Nvivo 10. Segments of the recording were attached to the transcriptions. Thus, the researcher could retrieve the data (from the transcriptions or the recordings) easily when she examined the diagram of the influencing factors.

During the open coding, the researcher considered a set of questions, such as "What is gender identity?"; "What is meant by being a T, Bufen or Po?"; and "Why is it so important to maintain gender identity?" The codes were then examined for similarities and differences and then compared and clustered together to create categories. The audio recordings were verified at least five times to ensure coding accuracy, avoid misunderstandings of the participants' meaning in speech, and distinguish the differences and similarities among the participants. All of the code lists were discussed and examined by the research team, and modifications were made several times to form a concise code list. The categories were then systematically compared and contrasted to establish more inclusive categories.

Variations within the categories were investigated through constant comparison and by investigating negative cases. The search for negative cases, which seemed to contradict the 
emergent themes or categories, was an analytical strategy that aimed to improve the quality of the research accounts and acknowledge the importance of multiple perspectives (Seale, 1999). The researcher compared the audio-coding, subcategories, and categories with/within the participants. When a view was reported which was different from that of the majority of the participants, the reasons for this would be considered by looking at women's social and demographic background and their past experiences in relation to the topic. By the end of the data collection, no new themes emerged, the categories became saturated, and their relationships were established. Memos and diagrams were used throughout the data analysis process to document the analytical process and record ideas about the emerging codes and categories and their relationships.

\section{Results}

The lesbians' gender identities ( $\mathrm{T}$, bufen pian $\mathrm{T}$, bufen, or Po) were found to be associated with not only their gender-role constructions and views toward their own breasts, but also their breast health. In Taiwan, the bufen identity in the context of relationships is obscure; no specific conventions should be followed to be a bufen. The obscure identity of bufen lesbians was found to have varying perspectives regarding their own breasts, breast cancer, and breast cancer screenings, as well as different patterns of behaviours and intentions concerning breast cancer screenings. Therefore, in the current study, we mainly focused on the T- (comprising both T and bufen pian T lesbians) and Po-identified lesbians' constructions of gender roles and the associations between their views toward their own breasts and their breast healthcare behaviours and intentions. The following identifies T-identified lesbians' views toward their own breasts, constructions of T-identity, barriers to screenings due to $\mathrm{T}$ identity, and their masculine appearances as well as Pos' views toward their own breasts. Additional information about each participant who is quoted here can be found in Table 1. Definitions and examples of themes of Taiwanese lesbians' views toward their own breasts 
are summarized in Table 2.

\section{T-identified Lesbians' Views Toward Their Own Breasts}

Contradictory feelings. The T-identified lesbians in our study reported various negative views about their own breasts. These negative views inhibited their breast healthcare behaviours and intentions: "I usually ignore them [my breasts]. I do not know why I accepted to do this interview. Maybe I want to know how I really feel about my own body through this interview" (ID 14); "I have had them [my breasts] since I was born. I cannot change them. But in my mind, I feel there is a conflict between my body and my mind" (ID 17); "During my puberty, I did not like my body because this was not what I expected" (ID 25); "Our breasts [Ts' breasts] do not have any functions. We do not really care about them” (ID 34). The discordance between these T interviewees' female characteristics and their masculine identity led to negative feelings about their own breasts.

Guilt. Guilt was also reported as a negative feeling toward their own breasts: Most T [lesbians] feel guilty about their own body. Although I have already accepted that I am a woman, I cannot accept my female characteristics... When

I was young, my parents blamed themselves and asked God why they had a child different from other children... I felt sorry about who I was... I did not know how to face my parents during that period. (ID 22)

A negative body image and traditional cultural obligations were associated with this woman's feelings of guilt; she not only felt guilty because of the inconsistency between her female characteristics and her masculine identity, but also acknowledged that she could not satisfy traditional Taiwanese cultural obligations (e.g., being an obedient daughter or wife and having children). The woman's feelings of guilt were felt in relation to herself as well as her family. Notably, she could not be who she believed she really was: a man. Furthermore, she could not satisfy her family's expectations of her. 
Acceptance. Despite prior negative views, acceptance of their female characteristics was reported by nine T-identified lesbians: "I spent some time identifying myself. I have learnt to try to accept my own female body and live with it peacefully" (ID 12); "Women have breasts. I can accept them [my breasts], but I do not want to think or talk about them specifically" (ID 19); "I did not like them [my breasts] when I was young. But, I can accept them now. We [Ts] are born as women, we just like a person who has the same gender" (ID 24). A long-term negative body image might lead to emotional disturbance and even mental health problems, such as depression (Hamilton, 2008). To avoid body image disturbance, participants appeared to apply a concordance process, either consciously or unconsciously, which served to resolve the contradictions between their female bodies and their masculine identities, to integrate these women's expectations and experiences of their physical and psychological traits, and to develop new body image perceptions. These interviewees' views regarding their own breasts were positive because they had each experienced a process of concordance regarding their physical and psychological characteristics and had developed new body image perceptions.

Three key factors were found to motivate the concordance process among these women — namely, traditional Chinese culture, increasing age, and social stigma. According to traditional Chinese culture (e.g., the Classic of Filial Piety), people's bodies are derived from their parents; accordingly, people are prohibited from hurting their own body in any situation. Traditional Chinese culture forbids a person from making any alterations to his or her own body. Therefore, the disallowance of having sex reassignment surgery to remove their breasts was reported as a motivating factor of the concordance process, as described by one interviewee:

When I was young, I felt embarrassed about my breasts. But it was for a very short period of time. They are already there, and I cannot change them. So, [I 
am] content with them! I do not like or dislike them — they are just parts of my body. (ID 27)

This interviewee identified herself as masculine, stating that she felt embarrassed about her own breasts when she was young. However, she realised that there was nothing she could do to change her body; therefore, she passively accepted her female characteristics.

Ageing was noted as one of the reasons for beginning the concordance process: "I could not accept my breasts when I was young. I wanted to be a handsome boy. But I accept my own body because they are impossible to hide. I accept my breasts but I do not like them" (ID 10); "If I was in my 20s, I would probably have surgery to remove my breasts. But I am old now-I do not have to pretend to be somebody else. I do not dislike them, but I do not like them either" (ID 21). As the lesbians aged, they might have realised that their female characteristics could not be removed because of traditional Chinese cultural constraints; furthermore, regardless of their efforts to hide their breasts, they were still women physically. For the older of these two T interviewees, external identification might have become less crucial as she aged, possibly because she had a stable romantic relationship and belonged to various social groups.

Finally, social stigma was also expressed as a motivating factor of the concordance process by two T-identified lesbians:

I have accepted my female body because I am getting older and I do not want to make life too difficult for myself. A few years ago, I looked for a job, but it was very difficult to find one because I was not sure what kind of a job I was looking for - $\mathrm{a}$ job for a woman or a job for a man? If I did not acknowledge that I was a woman, I could not find a job. During that time, I was forced to identify myself as a woman in order to find a job in this society. (ID 37) 
Another T-identified lesbian stated that:

I was a securities specialist when I was in my 20 s. The company asked me to wear a uniform which was a women's dress. During that time, I had to choose whether to be myself or to do what the company asked me to do. (ID 03)

Transgender stigma, which refers to the stigma attached to people whose gender expression or comportment differs from societal gender norms (Institute of Medicine, 2011), was considered by the women as a motivating factor of the concordance process that was initiated to live in Taiwanese society and avoid body image disturbance.

\section{Constructions of T-identity: Breast Binding}

According to the aforementioned descriptions, most of the T-identified lesbians held negative views toward their own breasts. To avoid body image disturbance, constructing a masculine appearance in their daily lives was considered by the lesbians to be crucial. Furthermore, wearing breast bindings was reported to be the most common method of making their breasts invisible by the T-identified lesbians $(12 / 23 ; 52.2 \%)$.

Four reasons for wearing breast bindings were stated by the T-identified lesbians. One reason mentioned was that breast bindings were employed to respond to social expectations: "I wear breast bindings because I would like to make [my breasts] smaller. I do not know why I want to make them smaller, but this is what Ts [lesbians] do" (ID 16). In addition, strengthening gender identity was expressed as a reason for wearing breast bindings: "My partner is a Po; so, I do not like my female characteristics to be seen. It will make me feel uncomfortable" (ID 17). Finally, indicating sexual orientation and promoting sexual attraction were reported as two additional reasons for wearing breast bindings:

Other Ts have a flat chest and it looks good when they wear a suit. It is easier for them to find a partner. So, I think of how I want to dress like them and how this will probably help me to find girlfriends. (ID 19) 
No study participants reported being a member of a T-T or Po-Po lesbian couple. For the lesbians interviewed, the identification of their gender role was highly crucial in finding a suitable partner. Widely applied by T lesbians in Taiwan, wearing breast bindings was the most common method employed by the T-identified participants to construct their gender roles.

\section{Barriers to Screenings: T Identity and Masculine Appearance}

Ten T-identified lesbians $(10 / 23 ; 43.4 \%)$ reported negative intentions toward BSE because of their masculine identity and their views toward their own breasts. Four of the ten women stated that they did not like thinking about any concerns regarding their own breasts or approaching any related information or healthcare services. Moreover, because of social stigma, their masculine appearance and defeminisation were identified as major inhibitors of the women's behaviour and intentions toward mammograms.

Previous medical and social experiences of being discriminated against because of their masculine appearance were reported as barriers to attending breast cancer screenings by five T lesbians $(5 / 23 ; 21.7 \%)$. Even if the women had never had a screening, they stated concerns about having hospital breast screenings. Possible discrimination regarding their masculine appearance was noted as a barrier to having mammograms: "It is not easy for me to have breast screenings. It is very difficult to change others' perceptions... I would worry about others' judgments while waiting for the examination. I would probably worry that others might talk about me.” (ID 05); "I worry about how others might feel confused because of my appearance: ‘Are you a man or a woman?' Or others might look at me judgementally. All of these concerns will discourage me from having breast screenings" (ID 30). Fear of discrimination because of their male appearance was described as inhibiting each interviewee's intention to undergo screening.

\section{Pos' Views about Their own Breasts}


Sexual attraction. For the Po lesbians, their breasts represented their female

characteristics. Their views regarding their own breasts were much more positive than were those of the T lesbians. Two Po lesbians reported the vital sexual function of their breasts: "I like my breasts the most in comparison with other parts of my body... My breasts are my female characteristics... My ex-partners liked my breasts too" (ID 13). The function of the women's breasts was mainly understood in relation to the sexual attraction of their partners. In contrast to the T lesbians, who bound their breasts to construct a masculine identity and promote sexual attraction, the Po lesbians increased their sexual attraction and strengthened their feminine identity by emphasising their female characteristics (e.g, their breasts) to find a suitable partner and maintain a relationship.

Breastfeed. In addition to sexually attracting their partners, breastfeeding was reported as another function of the Pos' breasts: "If I have a baby in the future, my breasts will be used to feed my baby" (ID 31); "I want to have a child in the future. I hope I can breastfeed my own baby" (ID 33). Given that they had a feminine role within their relationship, the participants associated their breasts' function with the traditional motherhood function (i.e., breastfeeding) perceived among heterosexual women. Participants adhered to the Po convention of assuming a female role within a relationship and believed that their breasts had a function associated with motherhood.

Parts of the women's bodies that represent female characteristics. Similar to heterosexual women in Taiwan, five Po-identified lesbians perceived their breasts as parts of their bodies that represented female characteristics: "My breasts are parts of my body" (ID 01); “Women's breasts are important female characteristics. If a woman lost her breasts, she is not a woman anymore" (ID 11); "They [my breasts] are not only organs but also parts of my body. Sometimes, my partners mistook that my breasts are only for sexual attraction" (ID 36). The Pos' views toward their own bodies were found to be similar to 
those of heterosexual women. Pos' gender identity and their construction of Po-identity were not reported as barriers to breast cancer screenings in our study.

\section{Discussion}

In the current study, we found that Taiwanese lesbians' gender identity affected women's views toward their own breasts, construction of their appearances and their views, and intentions and behaviour regarding breast cancer screenings. The negative views that some participants held toward their own breasts were related to their gender identities, particularly among those who self-identified as T lesbians. Morrison and McCutcheon (2011) found that bodily discomfort among lesbians might be attributable to a variety of factors, including a lack of conformity to the cultural expectation of having a female appearance, particularly among lesbians identifying as androgynous. In addition, Zeng (2004) indicated that a higher inclination toward masculine behaviour among lesbians correlates with higher dissatisfaction concerning their own bodies. Most of the T-identified lesbians were dissatisfied with their female physiological traits and disliked having their breasts touched by their partners. Similar findings were also presented in Gunkel's (2009) study, in which masculine lesbians in Bulgaria expressed that they felt as though they were trapped in the wrong body; they attempted to hide or ignore their breasts, which indicated their female identity.

Feeling guilty was reported as a negative view toward these lesbians' own breasts. However, we found that feeling guilty might not only relate to the individual's views toward her female characteristics but also associate with her sexual orientation and her traditional cultural obligations. Within Taiwanese society, people usually have strong family ties due to influences of Confucian philosophy (Chien \& Yi, 2001). In Confucian philosophy, filial piety is a virtue of respect for one's parents, elders, and ancestors and maintaining family honour is perceived as more significant than is individual freedom (McGoldrick, Giordano, \& Garcia- 
Preto, 2005). Being a lesbian in Taiwan might bring self-conflicts between traditional cultural also satisfy one's own desire. Hence, feeling guilty might be associated not only with the woman's views toward her own body but also with her sexual orientation and failure of being an obedient daughter.

The construction of a masculine identity requires the projection of a masculine body appearance, involving a process of defeminisation that includes breast binding, hair shortening, and wearing masculine clothes (Chao, 2000, 2001). Similar lesbian practises were mentioned in Levitt and Hiestand's (2005) study, in which butch lesbians in the United States also underwent a process of socialisation whereby they internalised the meanings attached to gendered expressions in lesbian subculture and learned to read and express sexual messages. In a Taiwanese online survey by Kuang et al. (2004), over $70 \%$ of the 38 participating masculine lesbians reported attempts to hide their breasts. In the present study, over half of the T-identified lesbians reported using breast bindings to construct a masculine identity. The reasons for using breast bindings among the $\mathrm{T}$ lesbians in our study reflect those found in previous Taiwanese studies (e.g., Hong, 2013; Su, 2005). However, these acts of defeminisation were identified as barriers to the Ts' intentions to undergo breast cancer screenings in the current study. This finding corresponds to those of Hiestand et al. (2007), who determined that butch lesbians, compared with femme lesbians, were less likely to undergo routine gynaecological examinations and were more likely to avoid healthcare settings.

Negative views among the T lesbians toward their own breasts were noted as barriers in their breast healthcare behaviour and intentions. This finding corresponds with those of Fish and Wilkinson (2003), who explored how feelings of embarrassment and psychological discomfort when performing BSEs prevented British lesbians from undergoing breast cancer 
screenings. Although the studied lesbians reported that they believed that BSE should be

performed, they still felt uncomfortable about their bodies in general and specifically about their breasts. Among the participants in Fish and Wilkinson's study, strong negative feelings (e.g., nausea) were sometimes induced by the prospect of BSE; however, the study did not explore why these women held negative views toward their own bodies and breasts. Our study findings are useful to researchers because they fill the research gap concerning why lesbians hold negative views toward their own breasts and how these views might influence their breast healthcare behaviour and intentions.

Masculine-identified lesbians were found to be more likely than feminine-identified lesbians were to encounter sexist insults and homophobic comments (Chao, 2000; Kuang et al., 2004). In Taiwanese society, Ts' nonfeminine actions are viewed as threats to traditional Chinese culture. In our study, concern about being discriminated against was one of the most critical barriers to the Ts' behaviour and intentions toward hospital mammograms. Similar findings can also be seen in previous international studies. Butch women were reported to experience more discrimination based upon their sexual orientation than were femme women or women with nontraditional gender expressions, and they faced significantly more discrimination based upon their gender expression (Levitt \& Hiestand, 2004; Levitt \& Horne, 2002; Levitt, Puckett, Ippolito \& Horne, 2012). Mitra and Globerman (2014) also indicated that anti-gay violence and a lack of an adequate lesbian-supportive environment were barriers in lesbians' healthcare. On the other hand and importantly, Po-identified lesbians' gender identity and construction of their female appearances were not found to be related to their breast healthcare intentions and behaviour.

\section{Limitations and Future Research Directions}

Some limitations should be noted. First, the current participants were recruited if they self-identified as a lesbian or were a woman who had a partner of the same gender - similar 
to previous relevant research enrolling lesbian participants. However, this necessarily excluded lesbians who did not self-identify as lesbians or had a partner of the same gender. Second, according to evidence obtained from U.S. (Peplau, Fingerhut, \& Beals, 2004; Walker, Golub, Bimbi, \& Parsons, 2012) and UK (Farquhar, 2000) studies, contemporary lesbians' gender identity in these two counties is usually flexible and fluid and cannot be neatly classified as a butch or femme identity. Nevertheless, in Taiwan, most lesbians apply binary gender labels ( $\mathrm{T}$ or Po); furthermore, there are more $\mathrm{T}$ lesbians than Po lesbians, according to our study findings and those of a previous Taiwanese study (Zhang, 2011). Therefore, the applicability of the findings herein might be limited to lesbians sharing similar racial, cultural, or subcultural practises. Thirdly, due to the small number of T- or Poidentified lesbians in the current study, further study is needed to understand whether the interview findings can be applied to a larger population.

\section{Practice Implications}

Our study's results can be applied by general populations who are interested in understanding lesbians' body image and professionals in varied areas, especially healthcare providers and policymakers. Our results can aid healthcare providers in understanding possible reasons for low utilisation rates of breast cancer screenings among T-identified lesbians, and they also can be used for designing and providing competent care that is sensitive to masculine lesbian culture. For example, a safe, protective, and private examination environment needs to be provided for these T-identified lesbians in order to maintain their identities. In order to maintain masculine lesbians' body image, healthcare providers should also consider how to provide a safe breast screening procedure (for example, how to maintain privacy during the screening procedure) and to develop a trusting relationship with their patient. Developing a trusting relationship should be seen as the first step in improving lesbians' breast health. Without trust, lesbians find it difficult to "come out" 
and to express what they need for their health.

Our results also can help policymakers in formulating related policy. For example, a sensitive and effective policy should (a) indicate the importance of providing culturally competent care to the target population, (b) make it clear that breast cancer screenings are not only for heterosexual women but also for all women (LGBTQI; lesbian, gay, bisexual, queer and intersex) who need the screenings, (c) acknowledge that women who need breast cancer screenings may have varied sexual orientations and gender identities, (d) be designed to encourage hospitals and healthcare providers to provide culturally competent care as well as support any relevant training courses provided to healthcare providers and students, and (e) modify documents used for collecting health information to be LGBT-inclusive.

\section{Conclusion}

The current study found that Taiwanese lesbians' gender identity affected these women's views toward their own breasts as well as their construction of their gender role and therefore their breast health, particularly among T-identified lesbians. In order to encourage Taiwanese lesbians' utilization of breast cancer screenings and to promote their breast health, healthcare providers should provide relevant information regarding breast health and culturally competent care to women, and policymakers should formulate suitable policy to meet diverse women's needs. 


\section{References}

Abate, M. A. (2011). Introduction: Special issue on tomboys and tomboyism. Journal of Lesbian Studies, 15(4), 407-411. doi:10.1080/10894160.2011.532026

Cahill, S. R., Baker, K., Deutsch, M. B., Keatley, J., \& Makadon, H. J. (2016). Inclusion of sexual orientation and gender identity in stage 3 Meaningful Use guidelines: A huge step forward for LGBT health. LGBT Health, 3(2), 100-102. doi:10.1089/lgbt.2015.0136

Chan, L. R. (2000). Their stories: Seven lesbian's lief experiences (Master's thesis). Retrived from National Digital Library of Theses and Dissertation in Taiwan at http://handle.ncl.edu.tw/11296/ndltd/72382436686084981323

Chao, A. (1997). Sex, conceptions of sex and body constructions. Paper presented at the Sex/Gender research: $1^{\text {st }}$ LGBT conference, Taipei. Retrived from http://sex.ncu.edu.tw/publication/1997/4sexpaper_1/pdf/01-4.pdf

Chao, A. (2000). Global metaphors and local strategies in the construction of Taiwan's lesbian identities. Culture, Health \& Sexuality, 2(4), 377-390. doi:10.1080/13691050050174404

Chao, A. (2001). Drink, stories, penis, and breasts: Lesbian tomboys in Taiwan from the 1960s to the 1990s. Journal of Homosexuality, 40(3-4), 185-209. doi:10.1300/J082v40n03_10

Chao, A. (2002). 'How come I can't stand guarantee for my own life?': Taiwan citizenship and the cultural logic of queer identity. Inter-Asia Cultural Studies, 3(3), 369-381. doi:10.1080/1464937022000037499

Cheng, M. L. (1997). There is a women's community in Taiwan: Taiwan lesbians' gender, family and community life. Taipei: Nushu.

Chiang, W. S., \& You, M. H. (2011). A study on young lesbians' intimate relaitonhsips, sexula 
explorations and sexula practices. Chinese Journal of Guidance and Counseling, 31, 159-182. Retrived from http://tci.ncl.edu.tw/cgi-

bin/gs32/gsweb.cgi?o=dnclresource $\&$ s $=\mathrm{id}=\% 22 \mathrm{~A} 12019254 \% 22 . \&$ searchmode $=$ basic \&tcihsspage=tcisearch_opt1_search

Chien, W., \& Yi, C. (2001). The dynamic development of Taiwanese families structural fission and expansion. Journal of Population Studies, 23, 1-47. http://www.popline.org/node/186262

Clark, M. A., Bonacore, L., Wright, S. J., Armstrong, G., \& Rakowski, W. (2003). The cancer screening project for women: Experiences of women who partner with women and women who partner with men. Women Health, 38(2), 19-33. doi:10.1300/J013v38n02_02

Clark, M. A., Rogers, M. L., Armstrong, G. F., Rakowski, W., Bowen, D. J., Hughes, T., ... McGarry, K. A. (2009). Comprehensive cancer screening among unmarried women aged 40-75 years: Results from the cancer screening project for women. Journal of Women's Health, 18(4), 451-459. doi:10.1089/jwh.2008.1046

Corbin, J. M., \& Strauss, A. (1990). Grounded theory research: Procedures, canons, and evaluative criteria. Qualitative Sociology, 13(1), 3-21. doi:10.1007/bf00988593

Corbin, J., \& Strauss, A. (2008). Basics of qualitative research: Techniques and procedures for developing grounded theory (3rd ed.). Thousand Oaks, CA: SAGE.

Corbin, J., \& Strauss, A. (2015). Basics of qualitative research: Techniques and procedures for developing grounded theory (4th ed.). Los Angeles, CA: SAGE.

Farquhar, C. (2000). Lesbian in a post-lesbian world? Policing identity, sex and image. Sexualities, 3(2), 219-236. doi:10.1177/136346000003002007

Fish, J., \& Wilkinson, S. (2003). Understanding lesbians' healthcare behaviour: The case of breast self-examination. Social Science \& Medicine, 56(2), 235-245. doi: 
$10.1016 / \mathrm{S} 0277-9536(02) 00022-9$

Fishel, T. (1994). Extending the limits of social construction: Female homosexuality in Taiwan. Historical Reflections/Reflexions Historiques, 20(2), 267-286. Retrieved from http://www.jstor.org/stable/41298997

Gunkel, H. (2009). Through the postcolonial eyes: Images of gender and female sexuality in contemporary South Africa. Journal of Lesbian Studies, 13(1), 77-87. doi: $10.1080 / 07380560802314219$

Halberstam, J. (1998). Female masculinity. London: Duke University Press.

Halcomb, E. J., \& Davidson, P. M. (2006). Is verbatim transcription of interview data always necessary? Applied Nursing Research, 19, 38-42. doi:10.1016/j.apnr.2005.06.001

Hamilton, S. R. (2008). A relationship between perceived body image and depression: How college women see themselves may affect depression. Student Journal of Psychological Sciences, 1(1), 13-20. Retrieved from https://www.msudenver.edu/media/content/psychjournal/4.pdf

Hiestand, K. R., Horne, S. G., \& Levitt, H. M. (2007). Effects of gender identity on experiences of healthcare for sexual minority women. Journal of LGBT Health Research, 3(4), 15-27. doi:10.1080/15574090802263405

Holloway, I., \& Todres, L. (2007). Grounded theory. In K. Gerrish \& A. Lacey (Eds.), The research process in nursing (5th ed., pp. 192-207). Oxford: Blackwell.

Hong, J. S. (2013). A study on young lesbians' experiences of wearing breast binders. (Master's thesis). Retrived from National Digital Library of Theses and Dissertation in Taiwan at http://handle.ncl.edu.tw/11296/ndltd/13341616630095133850

Institute of Medicine. (2011). The health of lesbian, gay, bisexual, and transgender people: Building a foundation for better understanding.Washington, DC: National Academies Press. doi:10.17226/13128 
BODY IMAGE AND BREAST HEALTH

Institute of Medicine. (2013). Collecting sexual orientation and gender identity data in electronic health records: Workshop summary. Washington, DC: National Academy of Sciences. doi:10.17226/18260

Kuang, M., Mathy, R., Carol, H., \& Kazuhiko, N. (2004). The effects of sexual orientation, gender identity, and gender role on the mental health of women in Taiwan's T-Po lesbian community. Journal of Psychology \& Human Sexuality, 15(4), 163-184. doi:10.1300/J056v15n04_02

Levitt, H. M., Gerrish, E. A., \& Hiestand, K. R. (2003). The misunderstood gender: A model of modern femme identity. Sex Roles, 48(3-4), 99-113. doi:10.1023/A:1022453304384

Levitt, H., \& Hiestand, K. (2004). A quest for authenticity: Contemporary butch gender. Sex Roles, 50(9-10), 605-621. doi:10.1023/B:SERS.0000027565.59109.80

Levitt, H. M., \& Hiestand, K. R. (2005). Gender within lesbian sexuality: Butch and femme perspectives. Journal of Constructivist Psychology, 18(1), 39-51. doi:10.1080/10720530590523062

Levitt, H., \& Horne, S. G. (2002). Explorations of lesbian-queer genders. Journal of Lesbian Studies, 6(2), 25-39. doi:10.1300/J155v06n02_05

Levitt, H. M., Puckett, J. A., Ippolito, M. R., \& Horne, S. G. (2012). Sexual minority women's gender identity and expression: Challenges and supports. Journal of Lesbian Studies, 16(2), 153-176. doi:10.1080/10894160.2011.605009

Lopez, E. D., Khoury, A. J., Dailey, A. B., Hall, A. G., Chisholm, L. R., Lopez, E. D. S., . . Chisholm, L. R. (2009). Screening mammography: a cross-sectional study to compare characteristics of women aged 40 and older from the deep South who are current, overdue, and never screeners. Women's Health Issues, 19(6), 434-445. doi:10.1016/j.whi.2009.07.008 
McGoldrick, M., Giordano, J., \& Garcia-Preto, N. (2005). Ethnicity and family therapy. New York: Guilford Press.

Mitra, S., \& Globerman, J. (2014). Rapid response: Facilitators and barriers to health care for lesbian, gay and bisexual (LGB) people. Toronto: Ontario HIV Treatment Network. Retrieved from http://www.ohtn.on.ca/Pages/Knowledge-Exchange/RapidResponses/Documents/RR79.pdf

Morrison, T. G., \& McCutcheon, J. M. (2011). Gay and lesbian body images. In T. F. Cash \& L. Smolak (Eds.), Body image: A handbook of science, practice, and prevention (2nd ed., pp. 214-220). New York: Guilford Press.

Peng, S. Y. (2008). Love and hate-Lesbian's views towards her own breasts. Paper presented at the Sex, Body and Relationship: Transformation and Integration Conference, Kaohsiung, Taiwan. Retrived from http://www.feminist.sinica.edu.tw/teach/teach22008.05.17.pdf

Peplau, L. A., Fingerhut, A., \& Beals, K. P. (2004). Sexuality in the relationships of lesbians and gay men. In J. Harvey, A. Wenzel, \& S. Sprecher (Eds.), Handbook of sexuality in close relationship (pp. 349-369). Mahwah, NJ: Erlbaum.

Robson, C. (2011). Real world remorrisosearch: A resource for users of social research methods in applied settings (3rd ed.). Chichester: Wiley.

Seale, C. (1999). Quality in qualitative research. Qualitative inquiry, 5(4), 465-478.

Su, S. K. (2005). T/Po identitiy within a relationhship in Taiwan (Master's thesis). Retrived from National Digital Library of Theses and Dissertation in Taiwan at http://handle.ncl.edu.tw/11296/ndltd/70270013145372221904

Walker, J. N. J., Golub, S. A., Bimbi, D. S., \& Parsons, J. T. (2012). Butch bottom-femme top? An exploration of lesbian stereotypes. Journal of Lesbian Studies, 16(1), 90-107. doi:10.1080/10894160.2011.557646 
Zeng, C. (2004). Lesbian's health problems and its countermeasures. Zhongguo Xing Kexue, $3,39-41$.

Zhang, F. J. (Ed.). (2011). Unlimited love. Taipei: China Times. 
Table 1

Participants 'Characteristics and Their Practice of Breast Self-Examination

\begin{tabular}{|c|c|c|c|c|c|c|}
\hline ID & $\begin{array}{l}\text { Gender } \\
\text { identity }\end{array}$ & Age & $\begin{array}{l}\text { Relationship } \\
\text { status }\end{array}$ & Occupation & Educational Level & Breast Self-Exams \\
\hline 1 & Po & 30 & Partnered & Nurse & College & Yes (irregular) \\
\hline 2 & $\mathrm{~T}$ & 27 & Single & Attendant & Junior high school & No \\
\hline 3 & $\mathrm{~T}$ & 40 & Single & Self-employed & High school & Yes (only once) \\
\hline 4 & Bufen & 24 & Single & Clerk & College & No \\
\hline 5 & $\mathrm{~T}$ & 23 & Partnered & Student & College & No \\
\hline 6 & Po & 42 & Partnered & Writer & High school & Yes (irregular) \\
\hline 7 & $\mathrm{~T}$ & 38 & Partnered & Publisher & College & Yes (irregular) \\
\hline 8 & Po & 26 & Single & Research assistant & Graduate/professional degree & Yes (regular) \\
\hline 9 & $\mathrm{~T}$ & 35 & Single & Radiation technician & Graduate/professional degree & Yes (regular) \\
\hline 10 & $\mathrm{~T}$ & 36 & Partnered & Patent attorney & College & No \\
\hline 11 & Po & 28 & Partnered & Accountant & College & Yes (irregular) \\
\hline 12 & $\mathrm{~T}$ & 30 & Partnered & Artist & Graduate/professional degree & No \\
\hline 13 & Po & 30 & Single & Social worker & College & Yes (regular) \\
\hline 14 & $\mathrm{~T}$ & 31 & Partnered & Nurse & Graduate/professional degree & No \\
\hline 15 & Po & 21 & Partnered & Student & College & Yes (irregular) \\
\hline 16 & $\mathrm{~T}$ & 21 & Partnered & Student & College & Yes (irregular) \\
\hline 17 & $\mathrm{~T}$ & 22 & Single & Military personnel & High school & No \\
\hline 18 & Bufen & 35 & Partnered & Reporter & Graduate/professional degree & No \\
\hline 19 & $\mathrm{~T}$ & 37 & Single & Café Manager & High school & No \\
\hline
\end{tabular}




$\begin{array}{lclllll}20 & \text { Bufen } & 39 & \text { Partnered } & \text { Post-Doctoral Fellow } & \text { Graduate/professional degree } & \text { Yes (irregular) } \\ 21 & \mathrm{~T} & 52 & \text { Partnered } & \text { Retired } & \text { College } & \text { Yes (irregular) } \\ 22 & \mathrm{~T} & 47 & \text { Single } & \text { Saleswoman } & \text { High school } & \text { Yes (irregular) } \\ 23 & \text { Po } & 57 & \text { Partnered } & \text { Retired } & \text { College } & \text { No } \\ 24 & \mathrm{~T} & 25 & \text { Single } & \text { Student } & \text { College } & \text { Yes (irregular) } \\ 25 & \text { Bufen pian T } & 24 & \text { Single } & \text { Student } & \text { College } & \text { No } \\ 26 & \mathrm{~T} & 41 & \text { Partnered } & \text { Office manager } & \text { Graduate/professional degree } & \text { Yes (irregular) } \\ 27 & \text { Bufen pian T } & 30 & \text { Partnered } & \text { Translator } & \text { Graduate/professional degree } & \text { Yes (regular) } \\ 28 & \text { Bufen } & 32 & \text { Partnered } & \text { Unemployed } & \text { College } & \text { Yes (irregular) } \\ 29 & \text { Bufen pian T } & 25 & \text { Partnered } & \text { Unemployed } & \text { High school } & \text { Yes (irregular) } \\ 30 & \mathrm{~T} & 41 & \text { Single } & \text { Broker } & \text { College } & \text { Yes (irregular) } \\ 31 & \text { Po } & 28 & \text { Partnered } & \text { Military personnel } & \text { College } & \text { Yes (regular) } \\ 32 & \text { Bufen pian T } & 33 & \text { Partnered } & \text { Photographer } & \text { College } & \text { Yes (regular) } \\ 33 & \text { Po } & 28 & \text { Partnered } & \text { Commercial artist } & \text { College } & \text { No } \\ 34 & \mathrm{~T} & 35 & \text { Partnered } & \text { Student } & \text { Graduate/professional degree } & \text { Yes (regular) } \\ 35 & \mathrm{~T} & 24 & \text { Single } & \text { Chef } & \text { College } & \text { No } \\ 36 & \text { Po } & 33 & \text { Single } & \text { Saleswomen } & \text { High school } & \text { Yes (regular) } \\ 37 & \mathrm{~T} & 27 & \text { Partnered } & \text { Military personnel } & \text { College } & \text { Yes (irregular) }\end{array}$

Note . For gender identities, $\mathrm{T}=$ butch; $\mathrm{Po}=$ Femme; Bufen $=$ undifferentiated lesbian; Bufen pain $\mathrm{T}=$ undifferentiated lesbian with some butch identification. 
Table 2

Themes, Definitions, and Examples of Taiwanese Lesbians' Body Image

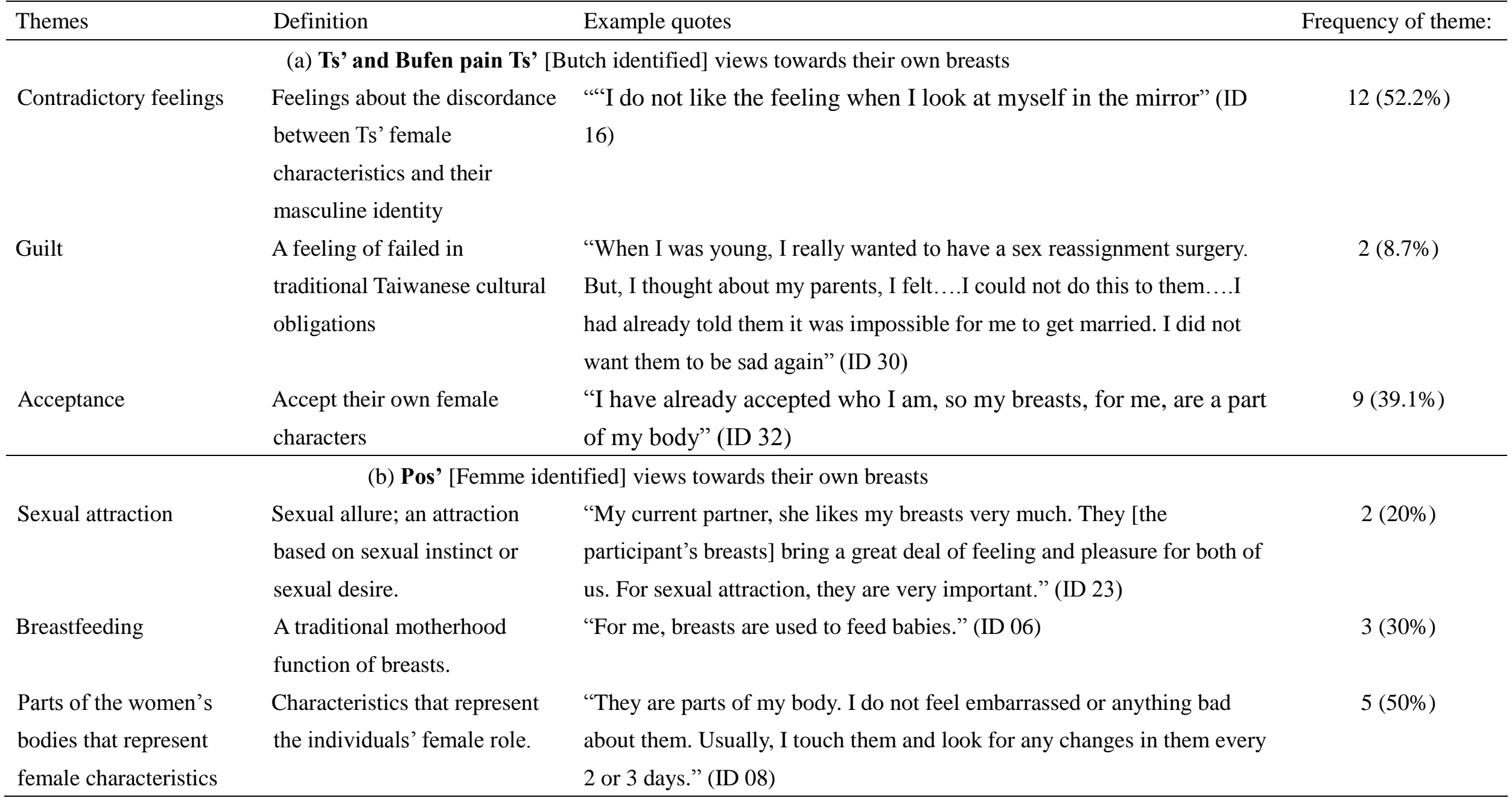




\section{Ethical approval for the qualitative interviews}

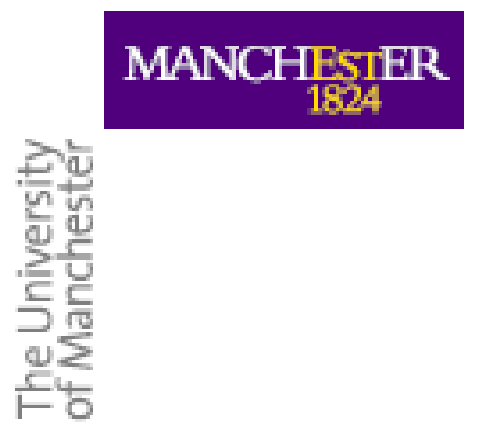

Faoulty of Engineoring and Phyrloal solenoed (Be2)

The Untversty of

Mancheeter

Sackwle Street Bulliding

Manchegter M13 SPL

$+44(0) 1613053084$

Adrien- Jarviagmanchablar : a

uk

Ref-AJ/ethics/110612

Ms. Wang

School of Nursing, Midwifery, and Social Work

$18^{\text {th }}$ July 2012

Dear Ms. Wang

Research Ethics Committee 3

Wang, Griffiths, Grande: Factors associated with Taiwanese lesbians' breast healthcare behaviours (ref 12122)

I write to confirm that the Chair is now satisfied that you have addressed the concerns of the Ethics Committee of the $11^{\text {th }}$ of July 2012 and has therefore given the above research project a favourable ethical opinion.

This approval is effective for a period of five years and if the project continues beyond that period it must be submitted for review. It is the Committee's practice to warn investigators that they should not depart from the agreed protocol without seeking the approval of the Committee, as any significant deviation could invalidate the insurance arrangements and constitute research misconduct. We also ask that any information sheet should carry a University logo or other indication of where it came from, and that, in accordance with University policy, any data carrying personal identifiers must be encrypted when not held on a university computer or kept as a hard copy in a location which is accessible only to those involved with the research.

Finally, I would be grateful if you could complete and return the attached form at the end of the project or by August 2013.

We hope the research goes well.

Yours sincerely

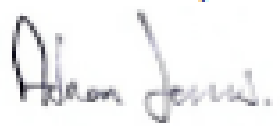

Adrian Jarvis

Ethics Committee 3 Secretary 


\section{Response to Reviewer Comments}

Please find the attachment (Revised manuscript), thank you very much. 